\title{
Determining the Effectiveness of Cognitive Therapy on Mindfulness-Based in Marital Fatigue and Women Intimacy
}

\author{
Maryam Mosalla1, Seyed Ali Aleyasin²* \\ ${ }^{1}$ MA, Department of Counseling, Faculty of Humanities, Khomein Branch, Islamic Azad University, Khomein, Iran \\ ${ }^{2} \mathrm{PhD}$, Department of Clinical Psychology, Faculty of Humanities, Khomein Branch, Islamic Azad University, Khomein, Iran \\ Email: *Aleyasin_psychology@yahoo.com
}

How to cite this paper: Mosalla, M. and Aleyasin, S.A. (2017) Determining the Effectiveness of Cognitive Therapy on Mindfulness-Based in Marital Fatigue and Women Intimacy. International Journal of Clinical Medicine, 8, 265-276.

https://doi.org/10.4236/ijcm.2017.84026

Received: March 16, 2017

Accepted: April 27, 2017

Published: April 30, 2017

Copyright $\odot 2017$ by authors and Scientific Research Publishing Inc. This work is licensed under the Creative Commons Attribution International License (CC BY 4.0).

http://creativecommons.org/licenses/by/4.0/

\section{(c) (i) Open Access}

\begin{abstract}
This research aimed at determining the effectiveness of cognitive therapy based on mindfulness in marital fatigue and married women intimacy. The semi-experimental research design with witness group and evaluation for pretest-posttest was used. The study population consisted of married women, referred to health counseling center in the 1st district of Tehran during 2016 and lasted about 1 year. Using random sampling method, were selected 30 married women referred to health counseling center in the 1st district of Tehran, whom the main reason for their visit was declared incompatibility and marital conflict. And 15 of those who would like to participate in training mindfulness-based cognitive therapy, were in the experimental group and 15 others were in the witness group. For experimental group, were presented mindfulness-based interventions in 8 sessions every session in one and a half hours. In this study, to collect data was to use two questionnaires: measure marital intimacy and marital fatigue. After collecting the results, data were entered into the software Spss and assumptions were evaluated using analysis of covariance. The results showed that the average of experimental group compared with the control group after the intervention health was significantly different in variables like: physical fatigue, mental disability, emotional banality, and intimacy $(\mathrm{p}=0.001)$. According to the findings above, it can be concluded that a mindfulness-based cognitive therapy training can reduce marital fatigue and as well as significantly effective in intimacy.
\end{abstract}

\section{Keywords}

Mindfulness, Marital Fatigue, Women Intimacy, Married Women

\section{Introduction}

The family is the smallest social institutions and its health and social stability, 
can have an effective role capability and stability of other institutions. In fact, the family, in the building creatures is ruling body cells and focus on maintaining family traditions and community. A family brings peace and harmony to society and if couples feel living together are favorable they will enjoy from the comfort and security and health. In the meantime, marital relationship has always been regarded as the longest and deepest relationship kind, because satisfactory marriage is beneficial for physical and mental health of couples [1]. Establishing and maintaining intimate relationships and satisfaction of emotional and psychological needs during the marriage, is an art and a skill that in addition to mental health and primary health experiences, requires gain logical insight, communication skills, life skills and perform his duties [2]. One of the variables examined in this study is marital fatigue or exhaustion. Marital fatigue or exhaustion is painfully physical, emotional and psychological condition that affects those who expect dramatic love gives meaning to their lives. This occurs when they realize their relationship, despite their efforts, did not give meaning to life. Pointlessness occurs because of the failures in love and it is the answers to the existing problems. Accumulation of psychological pressure attenuator love, a gradual increase in the incidence of boredom and monotony and gathering small annoyances help appearing pointlessness. [3] [4]. Emotional exhaustion occurs like: feeling depleted, being under pressure, discomfort, malaise and low mood [5] [6]. Mental fatigue is characterized as a decrease in self-esteem, feelings of despair and frustration toward his spouse, frustration and self-dislike [7] [8].

The aim of the current study is to determine the effectiveness of cognitive therapy on Mindfulness-based in marital fatigue and women intimacy in Iran.

\section{Literature Review}

Physical, emotional and psychological fatigue components can be equivalent with disillusionment. In other words, disillusionment is the first stage of marital. Disillusionment begins with feelings of anger and despair of the situation and gradually leads us into dissatisfaction. The continuation of this frustration, eventually brings the person in the second phase of depersonalization. Depersonalization also leads to give up and helplessness, i.e., marital burnout [9]. At first, the reaction to burnout may be that couples will try to regain the passion early in life. If these efforts fail, they will question their choice, and focus on the weaknesses and imperfections of each other and it'll be resulted in the intensification of frustration and anger. Some couples despite the lack of vitality still continue their marriage and another set, just be calm, when end their relationship [10]. Another variable examined in this study is intimacy. Psychologists define intimacy ability to communicate (unchecked), and express emotions (no inhibition) and it is mankind's natural condition [11] [12]. Intimacy-process in which the people are trying to approach each other and discover similarities and differences in their feelings and thoughts [13]. Knows the intimacy basic requirements, and defines it: being familiar, parallels and personal relationships mostly emotional love with someone else, which requires knowledge and deep under- 
standing of the other person, accept and express thoughts and feelings. And knows it a sign of love threshold. So intimate, interactive process, which is grounded by knowing, understanding, acceptance, rejection, empathy with the feelings of others and appreciate his/her unique view of the world [14].

According to these definitions of intimacy, we can know the agreements in couples, the true love and affection to each other and the obligations of the dimensions, aspects of the intimacy [15] [16] [17]. [18] describes intimacy in its numerous forms but all of them know intimacy a feeling of disclosure, near and partake in someone else's private world [19]. This feature refers to the interaction between spouses and its lack or absence is an indicator of disturbance in the marital relationship [20]. Based on [21], when intimacy becomes clear that the marriage function is well and a lack of intimacy shows that the marital relationship is weak. Enjoy the intimacy between married couples, is an important factor in the creation of stable marriages. [22] stated that avoid intimate relationships, is the factors that caused the failure in family life [23]. Studies and clinical experience show that in modern society, couples experience severe and pervasive problems when establishing and maintaining intimate relationships and compatible with each other [24].

In recent years, the role of cognitive factors in understanding the dynamics of interactions and relationships further considered, which may be cited such structural approaches, mental dynamics, communication, behavior, social learning. Affected the above approaches, prevention patterns and variety educational programs was also proposed. While these patterns have differences in theory, objectives, processes and intervention pattern, but also have common aspects together. Some of these programs include marriage enrichment program, strengthen relationships, couples communication, prevention programs and strengthen the relationship and so on. In these programs underlined on topics such as communication, negotiation, conflict resolution, self-awareness, commitment and responsibility, expectations, strengthen intimacy and sexuality, cognitive restructuring, etc.

One of the new methods that can be a useful in this field is: mindfulness-based interventions that can be considered as a cognitive and behavioral approach practices. Mindfulness-based interventions are considered as a treatment for cognitive-behavioral therapy is the third-generation or third wave. Mindfulness means paying attention in a particular way, focused on objective and the present moment without judgment. Also included keeping alive the consciousness of the present reality [25]. Since marital burnout accompanied with a sense of alienation, apathy and indifference between couples and replace negative emotions than positive emotions, creates a lot of dysfunctional thoughts in people, which determine and control the dysfunctional thoughts and negative emotions (such as depression, anxiety, etc.), cognitive therapy can have favorable results. Research results show that mindfulness-based cognitive therapy in the treatment of symptoms of depression, anxiety and decrease negative thoughts was more effective than cognitive therapy [26]. On the other hand, some studies have shown 
that happy couples conceptual harmony (intimacy) than unhappy couples have shown [27]. Conceptual harmony is a sign of mindfulness in the sense that the degree of enthusiasm husband or wife, to reappraisal thoughts about the spouse can assess the degree of resilience and flexibility they have in different situations.

Considering that the marital intimacy can transform the family's base to the strongest growth and human development in a society, and marital burnout can lead to marital dissatisfaction and to undermine foundation of the family, the aim of this study was to determine the effectiveness of mindfulness-based cognitive therapy on marital burnout and Intimacy of married women. And plans to pay it whether mindfulness-based cognitive therapy is effective on burnout and marital intimacy? Current study puts his work to answering a question of two hypotheses that include: 1) Mindfulness-based cognitive intervention is effective in reducing burnout marital married women. 2) Mindfulness-based cognitive interventions are effective in encouraging intimacy of married women.

\section{Materials and Methods}

\subsection{Research Method, Society and Samples}

The study used a quasi-experimental study with witness group as pretest-posttest for the evaluation. The study population consisted of married women, referred to health counseling center in the 1st district of Tehran. Using random sampling method, were selected 30 married women Randomly referred to health counseling center in the 1st district of Tehran, whom main reason for their visit were declared incompatibility and marital conflict (Lack of agreement and disagreement between the two couples, inconsistency in opinions, goals and behavior, which are taken in opposition to the another, and conflicts between people because of antithetic interests and different objectives and different perceptions). And 15 of those who would like to participate in training mindfulness-based cognitive therapy, were in the experimental group and 15 others were in the witness group. For this experimental study, after obtaining the necessary permits for the sampling and coordination for classes at health counseling center in the 1st district of Tehran, at the beginning, pre-test was performed on all participants. In the next step, mindfulness-based cognitive therapy sessions were presented treatment for the experimental group in eight sessions of 1,5 hours based on a plan that has been developed by Segal, Teazdel and Williams. In each session, after reviewing homework and provide a brief explanation about the previous meeting and explanations about the subject of the present session, exercises were performed. At the end of all educational sessions, feedback was obtained from the participants. In addition, an audio copy of mindfulness training and a summary of each session, were given to the participants to do practices at home between training sessions. One week after the last session of mindfulness training on the experimental group, post-test was performed for both groups. After the intervention, on the experimental group to determine the effect of this treatment in the longest follow-up time for 2 months was performed. Table 1 is a summary of the activities of treatment in each of the eight sessions. 
Table 1. Mindfulness-based cognitive therapy meetings general schema.

\begin{tabular}{|c|c|}
\hline First session: Autopilot & $\begin{array}{l}\text { Member acquaintance-the creating of the therapeutic } \\
\text { relationship-process of holding sessions-practice } \\
\text { eating raisins-body checking practice }\end{array}$ \\
\hline $\begin{array}{l}\text { Session II: Challenges with } \\
\text { obstacles }\end{array}$ & $\begin{array}{l}\text { body checking practice-ten minutes conscious breathing } \\
\text { exercises-thoughts and feelings practice }\end{array}$ \\
\hline $\begin{array}{l}\text { Session III: Mindfulness of } \\
\text { Breathing }\end{array}$ & $\begin{array}{l}\text { Sitting meditation focusing on awareness of breathing and } \\
\text { body-breathing space for three minutes-review pleasant week } \\
\text { interactive experiences and physical sensations, thoughts, } \\
\text { feelings and related mood experiences }\end{array}$ \\
\hline Session IV: Stay in the present & $\begin{array}{l}\text { Five minutes a conscious vision or hearing-sitting meditation } \\
\text { with awareness of breathing, body sounds and thoughts-walk } \\
\text { consciously-a breathing space for three minutes-review } \\
\text { interactive unpleasant physical sensations, thoughts, } \\
\text { feelings and related mood experiences }\end{array}$ \\
\hline $\begin{array}{l}\text { Session V: Acceptance and } \\
\text { permission/license being } \\
\text { present }\end{array}$ & $\begin{array}{c}\text { Sitting meditation, with awareness breathing and body-practice } \\
\text { letting to emotional experiences of "being" without judging } \\
\text { or trying to change them-experience } \\
\text { educational avoid using metaphors }\end{array}$ \\
\hline $\begin{array}{l}\text { Session VI: Thoughts } \\
\text { are not facts }\end{array}$ & $\begin{array}{l}\text { Sitting meditation, with awareness of breathing and body-a } \\
\text { breathing space for three minutes-exercise, think and } \\
\text { alternative views, emphasizing the fact that thoughts } \\
\text { are not facts-preparing for the end sessions }\end{array}$ \\
\hline $\begin{array}{l}\text { Session VII: How can I take } \\
\text { care of myself in the best way? }\end{array}$ & $\begin{array}{l}\text { Sitting meditation, with awareness of breathing and body, } \\
\text { sounds, thoughts and emotions-a breathing space for three } \\
\text { minutes-review the relationship between activity and mood }\end{array}$ \\
\hline $\begin{array}{l}\text { Session VIII: Use what you } \\
\text { have learned to cope with next } \\
\text { mood states }\end{array}$ & $\begin{array}{l}\text { Body checking exercise-discussion about the use of } \\
\text { mindfulness training in daily routine and problems } \\
\text { that hinder doing homework }\end{array}$ \\
\hline
\end{tabular}

\subsection{Research Tools}

\subsubsection{Couple Burnout Measurement (CBM)}

Scale of marital boredom is a self-assessment tool to measure the degree of marital boredom of couples. This scale of self-assessment tool borrowed from another self-assessment tool to measure boredom. This scale was invented by Pines. Couple Burnout Measurement has 21 articles that include three main components of physical fatigue (e.g. tiredness, lethargy and having sleep disturbance) emotional breakdown (feelings of depression, hopelessness, in entrapment) and mental breakdown (such as feelings of worthlessness, frustration and anger spouse). All of these items are answered on a seven-point scale [27] [28] [29]. Validity coefficient assessment of marital boredom scale showed that it has an internal consistency between variable in range of 0.84 and 0.90 . The validity is approved by negative correlation with positive communication features. Test-retest reliability for a one month was $0.89,0.76$ for a period of two months, and 0.66 for the four-month period. Internal continuity for most of the subjects was measured by constant coefficient Alpha, which is between 0.91 and 0.93 [30] [31]. 


\subsubsection{Inventory of Marital Intimacy}

This scale has been prepared by Walker and Thompson. This is a 17-item tool used to test love and intimacy. Scores range from 1 (never) to 7 (always), that the higher score is a sign of intimacy. This scale with Alpha 0.91 to 0.97 contains good consistency [32] [33]. Total score of test can be achieved through total scores of questions and dividing it by the number 17. This measure is part of a larger tool that encompasses several dimensions of intimacy but has been reported by providers like independent measurements. The validity of the method and content validity was examined. So that many of these masters field of counseling and psychology check questionnaire, and stated that tool measures marital intimacy [34].

\subsection{Analyze Data}

In this study, 23 SPSS software was used for statistical analysis. Describing the data, was used descriptive statistics indexes such as mean and standard deviation (in the pre-test and post-test and follow-up) and used in the inferential analysis of covariance.

\section{Results}

In findings part, first of all were studied the mean and standard deviation of the research variables in experimental and control groups and the two pre-test and post-test course are on the Table 2.

As shown in Table 2, the average post-test of witness group on variables of physical fatigue, mental and emotional burnout and marital burnout and intimacy has been reduced compared with the control group and the experimental group's average increase more in intimacy compared with the control group. To check the significant difference in the average obtained in Table 2, the analysis

Table 2. Comparing the mean and standard deviation of the pre-test and post-test physical fatigue, emotional and mental disability in two groups.

\begin{tabular}{|c|c|c|c|c|c|}
\hline \multirow[b]{2}{*}{ Variable } & \multirow[b]{2}{*}{ Group } & \multicolumn{2}{|c|}{ Pre-test } & \multicolumn{2}{|c|}{ Post-test } \\
\hline & & Mean & $\begin{array}{l}\text { Standard } \\
\text { deviation }\end{array}$ & Mean & $\begin{array}{l}\text { Standard } \\
\text { deviation }\end{array}$ \\
\hline \multirow{2}{*}{ Physical fatigue } & witness & 16.40 & 1.72 & 16.26 & 1.57 \\
\hline & experiment & 19.20 & 1.85 & 15.33 & 0.975 \\
\hline \multirow{2}{*}{ Mental disability } & witness & 25.00 & 2.85 & 24.06 & 2.63 \\
\hline & experiment & 26.20 & 2.17 & 22.60 & 2.41 \\
\hline \multirow{2}{*}{ Emotional disability } & witness & 46.60 & 2.79 & 45.66 & $2 / 66$ \\
\hline & experiment & 49.26 & 3.45 & 43.00 & 2.47 \\
\hline \multirow{2}{*}{ Marital burnout } & witness & 88.00 & 3.16 & 86.00 & 3.96 \\
\hline & experiment & 94.66 & 3.35 & 80.93 & 5.27 \\
\hline \multirow{2}{*}{ Intimacy experiment } & witness & 69.33 & 5.48 & 67.60 & 5.47 \\
\hline & experiment & 75.46 & 5.42 & 80.20 & 2.48 \\
\hline
\end{tabular}


of covariance was used. Before performing the analysis of covariance, the presuppositions of the test was discussed. To study the normal distribution of traits in groups was used test of Wilkes-Shapiro, which results in physical fatigue, the emotional and psychological burnout and marital burnout and intimacy variables was not significant statistically that represents a normal distribution trait in both study groups. The Levene test to check the homogeneity of variances for the above variables was not statistically significant, and the result suggests of the consistency of the variance of the studied variables. After checking the presuppositions of analysis of covariance, in Table 3, the results of covariance analysis are expressed for comparing two experimental and control groups in physical fatigue, emotional and mental burnout variable.

As is shown in Table 3 by controlling the pre-test between the experimental and witness groups, subjects in terms of the physical fatigue, mental breakdown and emotional disability there is a significant difference $(P=0.001)$. So that the Amount of effect or difference in physical fatigue variable equals 0.41 , means 42 percent of the individual differences, mental disability variable 0.70 means 70 percent of individual differences, and emotional disability variable 0.28 means $25 \%$ of individual differences, are recorded scores on Cognitive Intervention Effects on Mindfulness. So the hypothesis is confirmed about the effectiveness of mindfulness-based cognitive interventions to reduce marital burnout in married women. The Table 4 has been investigated to determine the effects of mindfulness-based therapy in the intimacy of married women.

As is shown in Table 4 by controlling the pre-test, between the experimental and witness groups of subjects there is a significant difference in terms of intimacy score $(\mathrm{p}=/ 001$ and $\mathrm{F}=55 / 87)$. The effect or difference equal to $/ 674$, about 67 percent of individual differences in intimacy scores of the effects of mindfulness-based cognitive intervention. Thus, this hypothesis is accepted.

Table 3. Results of covariance analysis on the post-test average scores of physical fatigue, mental and emotional burnout of the two groups with pre-test control.

\begin{tabular}{|c|c|c|c|c|c|c|c|}
\hline Variables & $\begin{array}{c}\text { Changes } \\
\text { source }\end{array}$ & $\begin{array}{l}\text { Sum of } \\
\text { squares }\end{array}$ & $\begin{array}{c}\text { Degrees of } \\
\text { freedom }\end{array}$ & $\mathrm{F}$ & $\begin{array}{c}\text { The } \\
\text { significance } \\
\text { level P }\end{array}$ & $\begin{array}{l}\text { Square } \\
\text { of Eta }\end{array}$ & $\begin{array}{c}\text { Statistical } \\
\text { power }\end{array}$ \\
\hline \multirow[b]{2}{*}{$\begin{array}{l}\text { Physical } \\
\text { fatigue }\end{array}$} & Pre-test & 18.135 & 1 & 16.250 & 0.001 & 0.376 & 0.973 \\
\hline & $\begin{array}{c}\text { Training } \\
\text { effect }\end{array}$ & 21.761 & 1 & 19.49 & 0.001 & 0.419 & 0.989 \\
\hline \multirow[b]{2}{*}{$\begin{array}{c}\text { Mental } \\
\text { disability }\end{array}$} & Pre-test & 158.695 & 1 & 215.98 & 0.001 & 0.889 & 1.00 \\
\hline & $\begin{array}{c}\text { Training } \\
\text { effect }\end{array}$ & 47.548 & 1 & 64.714 & 0.001 & 0.706 & 1.00 \\
\hline \multirow[b]{2}{*}{$\begin{array}{l}\text { Emotional } \\
\text { disability }\end{array}$} & Pre-test & 14.353 & 1 & $2 / 26$ & 0.144 & 0.077 & 0.306 \\
\hline & $\begin{array}{c}\text { Training } \\
\text { effect }\end{array}$ & 67.403 & 1 & 10.64 & 0.003 & 0.283 & 0.882 \\
\hline
\end{tabular}


Table 4. Analysis of covariance one-way on average scores of post-test intimacy of women in the two groups with pre-test control.

\begin{tabular}{ccccccc}
\hline $\begin{array}{c}\text { Changes } \\
\text { source }\end{array}$ & $\begin{array}{c}\text { Sum of } \\
\text { squares }\end{array}$ & $\begin{array}{c}\text { Degrees of } \\
\text { freedom }\end{array}$ & F & $\begin{array}{c}\text { The } \\
\text { significance } \\
\text { level P }\end{array}$ & Square of Eta & $\begin{array}{c}\text { Statistical } \\
\text { power }\end{array}$ \\
\hline pre-test & $286 / 568$ & 1 & $35 / 26$ & $/ 001$ & 1566 & $1 / 00$ \\
$\begin{array}{c}\text { Training } \\
\text { effect }\end{array}$ & $454 / 087$ & 1 & $55 / 87$ & $/ 001$ & 1674 & $1 / 00$ \\
\hline
\end{tabular}

\section{Discussion}

This study aimed to determine the effectiveness of mindfulness-based cognitive therapy on marital burnout and intimacy of married women in Khomeini Shahr. For this purpose, a sample of 30 married women were selected and after accomplishing the intended test and therapeutic intervention, the results obtained and the findings were discussed. The first finding of this research was that mindfulness-based cognitive therapy on physical fatigue, emotional and psychological disability of married women is effective. This finding is consistent with results of [35] [36] [37]. To explain these findings, it can be suggested that mindfulnessbased interventions associated with a set of formal meditation exercises, where participants are directing their attention in a particular way. This series of meditation exercises can be reduced and destroyed because of physical fatigue. Other methods are shorter or informal and insist on mindfulness in daily life [38]. These interventions include focused attention training where person focused his attention on a specific stimulus such as breathing, body sensations and so on, during a specific time period. To do this, are used mental and physical relaxation techniques and cognitive techniques also participants learned in exercises such as body checks and the three-minute breathing space focused their attention on the body or breathe and be relieved from the preoccupation with negative thoughts and minds to come out of auto mode and thereby reduced their physical fatigue. Also, after the emotional disability, marital burnout includes lack of passion, lack of satisfaction, emotional erosion and loss of motivation. People who are suffering from emotional disability feel that despite numerous attempts they do not reach the desired result. They may get angry in normal mode and feel that they have lost fun and vivacity sense [39] [40]. Emotional fatigue can make the person feel depleted, under pressure, discomfort, illness and inability [10]-[16]. Emotional disability includes feeling helplessness, hopelessness and gets tricked [18]-[33]. Marital burnout sufferers feel after the emotional disability, that there is no hope for them and their relationship point. So, every day they are sad and sadder. According to them, every day is worse than the day before. A mixture of physical and emotional symptoms of burnout in the mental disability caused changes in values, attitudes and beliefs of a person which gets nothing but more suffering and escapism [14] [15]. Mental disability or mental fatigue returns to grow their negative attitude towards work and life. These symptoms are normally seen in normal individuals [7] [8]. [9] believes that the person, who 
experiencing burnout shows symptoms of depression, irritability, hopelessness and low self- esteem and increase anxiety [20] [21] [22]. Mental disability or mental fatigue caused by burnout as a decrease in self-esteem and a negative opinion occur towards personal relationships and especially the relationship with the spouse. When a couple love each other, not only to themselves but to all aspects of life feel comfortable, but everything is done with the onset of fatigue. Couples strangely notice the smallest and most banal mistakes in the other party and quickly lose their patience and tolerance, and make life unbearable [11] [12].

The second study results show that mindfulness-based cognitive therapy is effective in intimacy of married women. The results are consistent with the results of research [25] [26] [27] [28]. This approach teaches people to be relieved of habitual thoughts rather than get involved with them and let the thoughts and feelings come and go, without having to be involved with them and try to take them away. In this treatment, people learn to stay in the present moment without having to worry about the future or the repeating past [39] and pay their attention to inner experiences at every moment like sensations, thoughts and feelings [37]. Person with the higher functions of the mind, including mindfulness, compassionate attitude and curiosity of mindfulness can effectively exert control emotional responses through inhibition of cortical limbic system [16]. So people who show higher levels of mindfulness, show less negative automatic thoughts and are able to leave their thinking [5]. On the other hand, since the happy couple and close have shown more Conceptual harmony (intimacy) than unhappy couples [2], mindfulness-based cognitive therapy can increase the resilience and flexibility in different positions by increasing person's desire to Reappraisal of thinking about the spouse.

\section{Conclusions}

In general, as is showed by the results presented in this study, it can be concluded that a mindfulness-based cognitive therapy can reduce marital burnout as well as significantly effective in intimacy. In total, according to data obtained in this study, efficiency and effectiveness of mindfulness-based cognitive therapy was confirmed on studied variables and it seems necessary to therapists and mental health experts for working with its clients, not to be satisfied to use only traditional treatments and do not negligence the use of new treatments like MBCT, which its effectiveness has been proven in various studies.

The study also included that restrictions, some of them may be noted: allocating results to women that prevent it from extending to the men community, interference factors such as socio-economic class subjects in research and having only one control group prevents the comparison of the effectiveness of mindfulness-based therapy with other treatments. Therefore, it is suggested by choosing other treatment option besides this treatment and using men resolve limitations of this study in future research. Also it is suggested that in order to improve their marital burnout we use the results of this study. Counseling centers and social welfare agencies can also hold regular workshops and courses with a focus on 
mindfulness-based cognitive therapy by taking a big step forward on improving relations between spouses.

\section{References}

[1] Adams, B. (2009) Athletic Training Education Program Director Burnout: Contributing Factors. PHD Dissertation, University of Dayton, Dayton.

[2] Chanofsky, S. (2009) Burnout throughout the Lifespan. PHD Dissertation, Widener University, Chester.

[3] Crawford, M. andUnger, R. (2004) Women and Gender: A Feminist Psychology. 4th Edition, McGraw-Hill, New York.

[4] Daghagheleh, F., Asgari, P. and Haider, A. (2012) Relation of Forgiveness, Love and Intimacy with Marital Satisfaction. Social Psychology (New Findings in Psychology), 7, 69-57.

[5] Dunham, S.M. (2008) Emotional Skillfulness in African American Marriage: Intimate Safety as a Mediator of the Relationship between Emotional Skillfulness and Marital Satisfaction. Doctoral Dissertation, University of Akron, Akron.

[6] Etemadi, A., et al. (2006) The Study Effect of Couples Therapy on Increasing Couples Intimacy in a Maggot Therapy Way, for Whom Referred to Counseling Centers in Isfahan. New Findings and Consulting Research, 5, 9-22.

[7] Hatfield, E. (1988) Passionate and Companionate Love in the Psychology of Love. Yale University Press, New Haven.

[8] Howell, A.J., Digdon, N.L. and Buro, K. (2010) Mindfulness Predicts Sleep-Related Self-Regulation and Well-Being. Personality and Individual Differences, 48, 419424.

[9] Huston, T.L. (2009) What's Love Got to Do with It? Why Some Marriages Succeed and Others Fail. Personal Relationship, 16, 301-327. https://doi.org/10.1111/j.1475-6811.2009.01225.x

[10] Babapour, et al. (2012) The Relationship of Meta-Cognition and Mindfulness Components with Obsessive Beliefs of Students. Journal of developmental psychology, 1, 23-38.

[11] Baer, R.A. and Krietmeyer, J. (2006) Overview of Mindfulness and AcceptanceBased Treatment Approaches. In: Baer, R.A., Ed., Mindfulness-Based Treatment Approaches, Academic Press, Burlington, 3-27.

[12] Bagarozzi, D. (2001) Enhancing Intimacy Marriage. Brunner/Routledge, Philadelphia.

[13] Wand, T. (2010) Mental Health Nursing from a Solution Focused Perspective. International Journal of Mental Health Nursing, 19, 210-219. https://doi.org/10.1111/j.1447-0349.2009.00659.x

[14] Blum, T.W. (2006) Becoming a Family Counselor: A Bridge to Family Therapy Theory and Practice. Wiley, Hoboken.

[15] Buunk, B.P. and Mutsaers, W. (1999) Equity Perceptions and Marital Satisfaction in Former and Current Marriage: A Study among the Remarried. Journal of Social and Personal Relationships, 16, 123-132. https://doi.org/10.1177/0265407599161007

[16] Jawaheri, H., Kaviani, F. and Bahiraii, H. (2008) The Effect of Mindfulness-Based Cognitive Therapy on Life Quality of Depressed People. Cognitive Science New Findings Year, 10, 39-48.

[17] Kabat Zinn, J. (2003) Mindfulness-Based Intervention in Context: Past, Present, and Future. Clinical Psychology. Science and Practice, 10, 144-156. 
https://doi.org/10.1093/clipsy.bpg016

[18] Kaya, O. (2010) Inclusion and Burnout: Examining General Education Teacher's Experiences in Turkey. PHD Dissertation, Indiana University, Bloomington.

[19] Kirby, J.S. (2005) The Interpersonal Process Model of Intimacy in Marriage: A Daily-Diary and Multilevel Modeling Approach. Journal of family Psychology, 19, 314325. https://doi.org/10.1037/0893-3200.19.2.314

[20] Kouhi, S. (2009) Predictors of Marital Frustration in Isfahan Couples. Family Counseling Master's Thesis, Faculty of Education and Psychology, University of Isfahan, Isfahan.

[21] Patrick, S., et al. (2007) Intimacy, Differentiation, and Personality Variables as Predictors of Marital Satisfaction. The Family Journal, 15, 359-367. https://doi.org/10.1177/1066480707303754

[22] Pines, A. (1996) What Make to Love Dream Not Lead to Disenchantment. Translation Fatemeh Shadab, F., 2002, Phoenix Publishing, Tehran.

[23] Rajabi, G., et al. (2014) Performance Studies Based on Acceptance and Adapted Commitment Couple, Integrated Behavioral Couples Therapy Based on Reducing Symptoms of Anxiety and Marital Conflict, Women, Who Have Marital Distress and Generalized Anxiety Disorder. Journal of Family Counseling and Psychotherapy, No. 1, 56-89.

[24] Rovine, M.J., Laurenceau, J.P. and Barrett, L.F. (2005) The Interpersonal Process Model of Intimacy in Marriage: A Daily-Diary and Multilevel Modeling Approach. Journal of Family Psychology, 19, 314-323. https://doi.org/10.1037/0893-3200.19.2.314

[25] Gong, M. (2007) Does Status in Consistency Matter for Marital Quality? Journal of Family Issues, 28, 152-161.

[26] Sanaei, B. (2000) Scale of Marriage and Family. Beast, Tehran.

[27] Segal, Z.V., Bieling, P., Young, T., Macqueen, G., Cooke, R. and Martin, L. (2002) Antidepressant Monotherapy vs. Sequential Pharmacotherapy and MindfulnessBased Cognitive Therapy, or Placebo, for Relapse Prophylaxis in Recurrent Depression. Genetic Psychiatry, 67, 1256-1264. https://doi.org/10.1001/archgenpsychiatry.2010.168

[28] Sharma, M.P., Mao, A. and Sudhir, P.M. (2012) Mindfulness-Based Cognitive Behavior Therapy in Patients with Anxiety Disorders: A Case Series. Indian Journal of Psychological Medicine, 34, 263-269. https://doi.org/10.4103/0253-7176.106026

[29] Siavashi, H. and Navabinejad, S. (2005) The Relationship between Marital and Irrational Beliefs Patterns of Teachers and Schools of Malayer. Journal New Findings and Research Consulting, 4, 9-34.

[30] Soltanizadeh, M. (2012) A Comparison of Cognitive-Behavioral Therapy, Metacognitive-Behavioral Therapy and Mindfulness-Based Cognitive Therapy on Marital Satisfaction, Anxiety and Depression in Men. PhD Thesis, Faculty of Education and Psychology, University of Isfahan, Isfahan.

[31] Teasdale, J.D., Segal, Z., Williams, J.M.G., Ridgeway, V.A., Soulsby, J.M. and Lau, M.A. (2000) Prevention of Relapse/Recurrence in Major Depression by Mindfulness Based Cognitive Therapy. Journal of Consulting and Clinical Psychology, 68, 615623. https://doi.org/10.1037/0022-006X.68.4.615

[32] Walker, A.B. and Thompson, L. (1983) Intimacy and Intergenerational Aid and Contact among Mothers and Daughters. Journal of Marriage and the Family, 45, 841-849. https://doi.org/10.2307/351796

[33] Wells, A. (2011) Meta-Cognitive Therapy for Anxiety and Depression. The Guilford 
Press, New York.

[34] Kuyken, W., Crane, R. and Williams, M. (2012) Mindfulness-Based Cognitive Therapy (MBCT) Implementation Resources. Mindfulness Centres at Exeter, Bangor and Oxford Universities, Oxford.

[35] Madani, Y. and Hojjati, S. (2015) The Effect of Mindfulness-Based Cognitive Therapy on Marital Adjustment and Quality of Life in Couples. Journal of Applied Psychological Research, 6, 60-39.

[36] Mazloumi, S. (2007) The Impact of Marriage Enrichment Program on Increasing Intimacy Couples without Problem. Family Counseling Master's Thesis, University of Welfare and Rehabilitation Sciences, Tehran University, Tehran.

[37] Navidi, F. (2005) Comparative Investigation of the Relationship between Marital Boredom with Organizational Factor in the Personnel Departments of Education and Hospital Nurse in Tehran. Senior Thesis in the Field of Counseling and Family Tendency, Shahid Beheshti University, Tehran.

[38] Oladi, Z. (2011) The Effectiveness of Group Therapy Based Reality Therapy to Reduce Boredom and Increase Marital Satisfaction of Married Women. Master's Thesis, Ferdowsi University of Mashhad, Mashhad.

[39] Omidi, A., et al. (2013) The Effectiveness of Combined Mindfulness-Based Cognitive Therapy with Cognitive Therapy and Classical Cognitive-Behavioral Therapy in Reducing Dysfunctional Attitudes of Patients with Depressive Disorders. Scientific Journal of Birjand University of Medical Sciences, 20, 383-392.

[40] Yousefi, N. and Sohrab, A. (2011) By Comparing the Effectiveness of MindfulnessBased Approaches to Family Therapy and Meta-Cognitive Effects of MindfulnessBased Cognitive Therapy in Marital Satisfaction and Marital Quality of Clients on the Verge of Divorcing. Journal of Counseling and Psychotherapy Family, No. 2, 192-211.

\section{Submit or recommend next manuscript to SCIRP and we will provide best} service for you:

Accepting pre-submission inquiries through Email, Facebook, LinkedIn, Twitter, etc. A wide selection of journals (inclusive of 9 subjects, more than 200 journals)

Providing 24-hour high-quality service

User-friendly online submission system

Fair and swift peer-review system

Efficient typesetting and proofreading procedure

Display of the result of downloads and visits, as well as the number of cited articles

Maximum dissemination of your research work

Submit your manuscript at: http://papersubmission.scirp.org/

Or contact ijcm@scirp.org 